\title{
Chinese Public's Attention to the COVID-19 Epidemic on Social Media: Observational Descriptive Study
}

Yuxin Zhao, MD; Sixiang Cheng, PhD; Xiaoyan Yu, MD; Huilan Xu, PhD

Department of Social Medicine and Health Management, Xiangya School of Public Health, Central South University, Changsha, China

\section{Corresponding Author:}

Huilan $\mathrm{Xu}, \mathrm{PhD}$

Department of Social Medicine and Health Management

Xiangya School of Public Health

Central South University

Xiangya School of Public Health, Central South University

Changsha, 410078

China

Phone: 8613637480958

Email: xhl csu@163.com

\section{Abstract}

Background: Since the coronavirus disease (COVID-19) epidemic in China in December 2019, information and discussions about COVID-19 have spread rapidly on the internet and have quickly become the focus of worldwide attention, especially on social media.

Objective: This study aims to investigate and analyze the public's attention to events related to COVID-19 in China at the beginning of the COVID-19 epidemic (December 31, 2019, to February 20, 2020) through the Sina Microblog hot search list.

Methods: We collected topics related to the COVID-19 epidemic on the Sina Microblog hot search list from December 31, 2019, to February 20, 2020, and described the trend of public attention on COVID-19 epidemic-related topics. ROST Content Mining System version 6.0 was used to analyze the collected text for word segmentation, word frequency, and sentiment analysis. We further described the hot topic keywords and sentiment trends of public attention. We used VOSviewer to implement a visual cluster analysis of hot keywords and build a social network of public opinion content.

Results: The study has four main findings. First, we analyzed the changing trend of the public's attention to the COVID-19 epidemic, which can be divided into three stages. Second, the hot topic keywords of public attention at each stage were slightly different. Third, the emotional tendency of the public toward the COVID-19 epidemic-related hot topics changed from negative to neutral, with negative emotions weakening and positive emotions increasing as a whole. Fourth, we divided the COVID-19 topics with the most public concern into five categories: the situation of the new cases of COVID-19 and its impact, frontline reporting of the epidemic and the measures of prevention and control, expert interpretation and discussion on the source of infection, medical services on the frontline of the epidemic, and focus on the worldwide epidemic and the search for suspected cases.

Conclusions: Our study found that social media (eg, Sina Microblog) can be used to measure public attention toward public health emergencies. During the epidemic of the novel coronavirus, a large amount of information about the COVID-19 epidemic was disseminated on Sina Microblog and received widespread public attention. We have learned about the hotspots of public concern regarding the COVID-19 epidemic. These findings can help the government and health departments better communicate with the public on health and translate public health needs into practice to create targeted measures to prevent and control the spread of COVID-19.

(J Med Internet Res 2020;22(5):e18825) doi: 10.2196/18825

\section{KEYWORDS}

COVID-19; Sina Microblog; public attention; social media; China; public health emergency; infodemic 


\section{Introduction}

The coronavirus disease (COVID-19) is a new infectious disease that is mainly transmitted by respiratory droplets and contact, and is generally infectious to human beings [1]. On January 11 , 2020, after pathogenic nucleic acid testing, China reported 41 cases of pneumonia that were infected with the novel coronavirus [2]. On January 30, 2020, the World Health Organization (WHO) listed the novel coronavirus epidemic as a Public Health Emergency of International Concern [3]. As of February 20, 2020, a total of 75,465 confirmed cases and 2236 deaths have been reported in mainland China [4]. The novel coronavirus has caused great challenges and threats to public health in China and has quickly become the focus of worldwide attention. Information and discussions about COVID-19 have spread rapidly online, especially on social media.

To fight against COVID-19 and promote the prevention and control of the epidemic, researchers have recently made efforts in various aspects. The research has involved topics such as epidemiological research [5-7], diagnostic methods for COVID-19 [8-11], clinical characteristics of the disease [12-16], characteristics of disease transmission [17-19], development of candidate therapies [20-22], and the identification of animal hosts [22-26]. However, there has been no research conducted on the public's attention to COVID-19. Since public participation is required to prevent and control the epidemic spread of infectious diseases, it is extremely important to learn about the public's attention toward COVID-19 during the current epidemic. Such knowledge is of great significance when guiding people to respond appropriately to the epidemic and helping them learn how to cope with the sudden infectious diseases such as COVID-19, and it also supports social stability [27].

Social media has developed rapidly in recent years. Increasing numbers of public health departments and individuals are using social media platforms to communicate and share information during public health emergencies. Social media has become an important channel for promoting risk communication during the crisis [28,29]. The use of social media to measure public attention has also been gradually applied to research on infectious diseases such as H7N9 [27,30,31], Ebola [28,32-36], Zika virus [29,37,38], Middle East respiratory syndrome-related coronavirus [39], and Dengue fever [40]. In addition, to help countries respond better to the spread of severe acute respiratory syndrome coronavirus 2 (SARS-CoV-2), the WHO has issued operational planning guidelines, requiring countries to take specific actions around the eight pillars. Risk Communication and Community Engagement, one of the eight pillars, plays an important role in health emergencies and requires the promotion of active public communication to clear public confusion and misunderstanding [41]. Since the outbreak of the novel coronavirus, Sina Microblog, the main social media platform in China, has become increasingly important for the public to communicate about the COVID-19 epidemic. Therefore, it is of immediate importance for governments and nongovernmental organizations to study the public's attention toward the COVID-19 epidemic on Sina Microblog.
Sina Microblog ("Weibo" for short) is one of the most popular social media platforms in China and is the equivalent of Twitter in China. As of the fourth quarter of 2018, the number of monthly active users had reached 462 million, and approximately 200 million people are using Sina Microblog every day [42]. The Sina Microblog hot search list is the ranking of the most followed and hottest information on Sina Microblog, and is the most popular functional module in Sina Microblog apps $[43,44]$. This ranking is sorted according to the search volume of the hot topics that users searched for within a certain period. The higher the search volume is, the higher the ranking is, which directly reflects the public attention and attitude toward the topic.

This paper studies the public attention given to COVID-19 on Sina Microblog by searching for and analyzing topics related to the COVID-19 epidemic on the Sina Microblog hot search list from December 31, 2019, to February 20, 2020. We use a Chinese social media platform, Sina Weibo, to study the public attention of COVID-19 [45]. In this study, we describe the trend of public attention given to topics related to the COVID-19 epidemic and the hot topic keywords of public concern, analyze the emotional tendencies and trends of hot topics related to the COVID-19 epidemic, and conduct a visual cluster analysis of the hot topic content. This approach is used to obtain timely access to public responses so that the government and the health department can better communicate with the public on health issues and take appropriate measures to prevent and control the epidemic [35,39].

\section{Methods}

\section{Research Overview}

The research process mainly included five steps: (1) collecting topics related to the COVID-19 epidemic on the Sina Microblog hot search list; (2) segmenting the collected text into words; (3) describing the Sina Microblog search trend around the COVID-19 epidemic; (4) evaluating public opinion through word frequency and sentiment analysis; and (5) constructing a social network of public opinion through the subject analysis of the content. Each step is described in detail below.

\section{Data Collection}

We obtained information on COVID-19 in mainland China from the National Health Committee of the People's Republic of China [46]. The Wuhan Municipal Health Committee first reported viral pneumonia of unknown causes on December 31, 2019 [47]. This study collected topics on the Sina Microblog hot search list from December 31, 2019, to February 20, 2020, using Weibo Search Rank [48] from ENLIGHTENT [49], and selected topics and their search volume related to the COVID-19 epidemic. A total of 4056 topics related to the COVID-19 epidemic were on the hot search list, and 3234 remained after excluding duplicate topics. This group was used as the data basis for further processing, analysis, and discussion.

\section{Data Processing}

The topics related to the COVID-19 epidemic on the Sina Microblog hot search list from December 31, 2019, to February 20,2020 , were summarized and classified daily in chronological 
order. We used the Chinese word segmentation function in ROST Content Mining System Version 6.0 (ROST CM6.0) to segment the content of hot search topics on Sina Microblog into words [50]. After word segmentation, the text was processed by merging synonyms and deleting nonsense words to provide a basis for subsequent research.

\section{Data Analysis}

\section{Trend Analysis}

We plotted the number of topics related to the COVID-19 epidemic on the Sina Microblog hot search list and the cumulative search volume by date to explore the public's attention toward the COVID-19 epidemic over time. A Pearson correlation analysis was used to explore the relationship between the number of hot search topics related to the COVID-19 epidemic and the cumulative search volume.

\section{Word Frequency and Sentiment Analysis}

After the Chinese word segmentation and invalid word filtering, we used ROST CM6.0 software to perform word frequency statistics and sentiment analysis on the Sina Microblog hot topics related to the COVID-19 epidemic. We calculated the frequency of keywords appearing in the hot search topics on Sina Microblog, explored the sentiment tendency of each hot search topic to the COVID-19 epidemic, and calculated the emotional score.

\section{Social Network Analysis and Visualization}

The high-frequency keywords and their frequencies were extracted from the Sina Microblog hot topic text after word segmentation and invalid word filtering. We used the VOSviewer software developed by Nees Jan van Eck and Ludo Waltman of the Centre for Science and Technology Studies of Leiden University in the Netherlands to create a visual knowledge map of keyword co-occurrence analysis and cluster analysis, using the keyword co-occurrence frequency as the weight [51].

\section{Results}

\section{Search Trend of COVID-19 Epidemic on Sina Microblog Hot Search List}

Figure 1 lists the number of COVID-19 epidemic-related topics and the cumulative search volume on the Sina Microblog hot search list from December 31, 2019, to February 20, 2020. The Pearson correlation analysis shows that the number of topics related to the COVID-19 epidemic is positively correlated with the cumulative search volume of the topic per day $(r=0.767$, $P<.001)$. In other words, the more topics that are listed, the greater the cumulative search volume related to the COVID-19 epidemic per day. We can see that the public's attention to the COVID-19 epidemic on Sina Microblog can be divided into three stages. Stage A (December 31, 2019, to January 18, 2020) has low and unstable public attention, which represents the incubation period. Stage B (January 19-26, 2020) has a concentrated increase in public attention, which represents the epidemic period. Stage C (January 27 to February 20, 2020) demonstrates continued public attention to the epidemic, representing a widespread period.

Figure 1. The number of topics and the cumulative search volume of the coronavirus disease epidemic on the Sina Microblog hot search list.

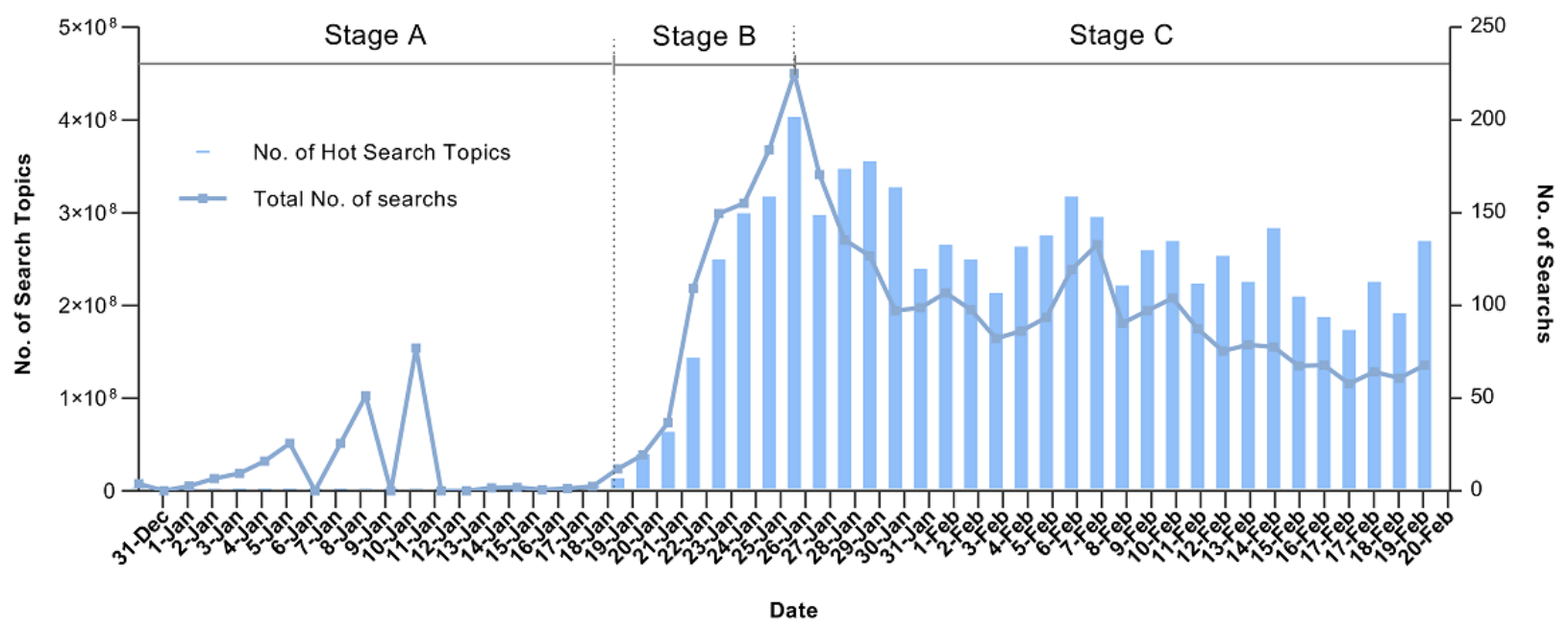

\section{Frequency and Distribution of Hot Search Keywords Related to the COVID-19 Epidemic on Sina Microblog}

The top 15 keywords and their frequencies for the three stages of the public's attention to the COVID-19 epidemic are shown in Table 1. "Wuhan," "case," and "pneumonia" always appeared in the three periods as hot keywords, and the remaining keywords in the different periods were slightly different. In stage A, "unknown cause" and "novel coronavirus" were the main keywords, indicating that in the initial stage of the epidemic, viral pneumonia had just been discovered, and the cause was unknown. After the pathogen was initially identified as a novel coronavirus, the public began to search for information on the novel coronavirus to learn relevant knowledge. Compared with stage A, stage B had new keywords such as "new," "mask," "first case," and "first-level response." The reason for this is that the COVID-19 epidemic had spread across the country during this stage. The first cases had appeared successively throughout the country, and the number of confirmed cases was increasing. The outbreak of COVID-19 
made the people and the government aware of the importance of prevention. People began to buy masks, and governments at all levels initiated first-level responses to major public health emergencies. Compared with the previous two stages, the main keywords appearing in stage C were "discharged," "national," "materials," and "Huoshenshan Hospital." At this stage, the public's attention had shifted to material donation and medical service assistance in the key epidemic areas in Wuhan. Moreover, the epidemic had spread throughout the country, and the public was more concerned about the rehabilitation of patients.

Table 1. Top 15 keywords about the COVID-19 epidemic on the Sina Microblog hot search list in the three periods.

\begin{tabular}{|c|c|c|c|c|c|c|}
\hline \multirow[t]{2}{*}{ Ranking } & \multicolumn{2}{|c|}{ Stage A (Dec 31, 2019, to Jan 18, 2020) } & \multicolumn{2}{|c|}{ Stage B (Jan 19-26, 2020) } & \multicolumn{2}{|c|}{ Stage C (Jan 27 to Feb 20, 2020) } \\
\hline & Keyword & Frequency, $\mathrm{n}$ & Keyword & Frequency, n & Keyword & Frequency, $\mathrm{n}$ \\
\hline 1 & Wuhan & 17 & COVID-19 & 141 & Wuhan & 316 \\
\hline 2 & Pneumonia & 14 & Wuhan & 124 & COVID-19 & 283 \\
\hline 3 & Unknown cause & 9 & Confirmed diagnosis & 87 & Case & 212 \\
\hline 4 & Novel coronavirus & 6 & Case & 84 & Confirmed diagnosis & 212 \\
\hline 5 & Patient & 5 & Add & 52 & Add & 199 \\
\hline 6 & Case & 5 & Masks & 37 & Epidemic & 190 \\
\hline 7 & Thailand & 4 & Epidemic & 31 & Hubei & 159 \\
\hline 8 & Leave hospital & 2 & Hubei & 29 & Masks & 149 \\
\hline 9 & Death & 2 & Startup & 25 & Patient & 149 \\
\hline 10 & $\begin{array}{l}\text { Person-to-person } \\
\text { spread }\end{array}$ & 2 & First case & 22 & Hospital & 98 \\
\hline 11 & Add & 2 & Pneumonia & 20 & Leave hospital & 90 \\
\hline 12 & Japan & 2 & Beijing & 20 & Nationwide & 83 \\
\hline 13 & COVID-19 & 2 & Patient & 19 & Beijing & 72 \\
\hline 14 & Epidemic disease & 2 & First-level response & 18 & Goods and materials & 59 \\
\hline 15 & Eliminate & 2 & Novel coronavirus & 17 & Huoshenshan hospital & 59 \\
\hline
\end{tabular}

${ }^{\mathrm{a} C O V I D-19:}$ coronavirus disease.

\section{Sentiment Analysis of the Hot Search Topics Related to the COVID-19 Epidemic on Sina Microblog}

After segmentation, we imported the Sina Microblog hot topic text related to the COVID-19 epidemic into the ROST CM6.0 sentiment analysis tool and obtained the sentiment and proportion of the three stages of public attention given to the topics related to the COVID-19 epidemic (Figure 2). Emotions were classified as positive, negative, and neutral emotions. Based on this, positive and negative emotions were subdivided into three categories: general, moderate, and high. Neutral emotions were not subdivided. We found that the sentiment of the hot topics of the COVID-19 epidemic on Sina Microblog in stage A tended to be negative, accounting for $58 \%(n=14 / 24)$, of which high and moderate negative emotions accounted for $13 \%(\mathrm{n}=3)$ and $17 \%(\mathrm{n}=4)$, respectively, and positive emotions accounted for the lowest proportion at $8 \%(n=2)$. In stage $B$, the majority of the hot search topics were neutral; however, $27.2 \%(n=174 / 639)$ of the hot search topics showed negative emotions, with $0.3 \%(\mathrm{n}=2)$ being highly negative and $3.6 \%$ $(\mathrm{n}=23)$ being moderately negative, while positive emotions accounted for $13.3 \%(n=85)$. In stage C, $18.01 \%(n=470 / 2610)$ of the hot search topics showed positive emotions, of which moderate positive emotions accounted for $2.26 \%(n=59)$ and highly positive emotions accounted for $0.31 \%(n=8)$; in addition,
$28.24 \%(n=737)$ of the hot search topics showed negative emotions. Based on the comprehensive analysis of the three-stage emotional tendencies, the public's negative emotions toward the COVID-19 epidemic were weakened as a whole, and their positive emotions were generally enhanced.

Figure 3 shows the trend for the proportion of the daily emotional tendencies of the hot search topics related to the COVID-19 epidemic from December 31, 2019, to February 20, 2020. We can see that the three kinds of emotions are relatively unstable before January 9, 2020. From January 9-20, 2020, negative emotions accounted for the largest proportion, followed by neutral emotions, and positive emotions accounted for the smallest proportion.

Compared with the emotions prior to January 20, 2020, the positive emotions of the hot search topics related to the COVID-19 epidemic after January 20, 2020, were generally on the rise; the negative emotions declined on the whole, and the emotions tended to be stable, as seen in Figure 3. This outcome shows that as the COVID-19 epidemic began to spread throughout the country after January 20, 2020, the public eased their concerns and fears caused by their uncertainty toward and ignorance of the epidemic, and responded to the epidemic with a more objective attitude. 
Figure 2. The sentiment statistics of the Sina Microblog hot search topics related to the coronavirus disease epidemic.

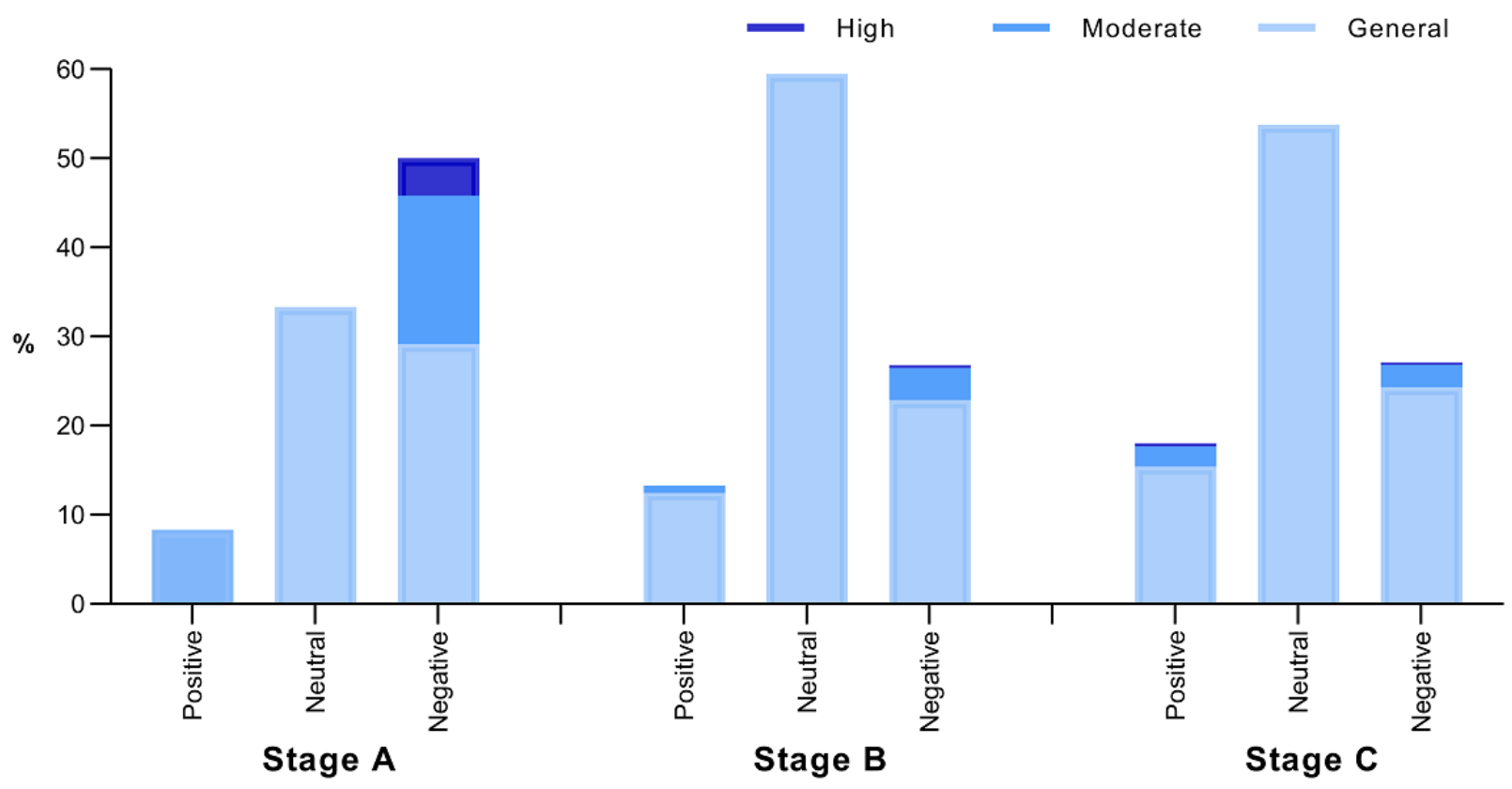

Figure 3. The sentiment trend of hot search topics related to the coronavirus disease epidemic from December 31, 2019, to February $20,2020$.

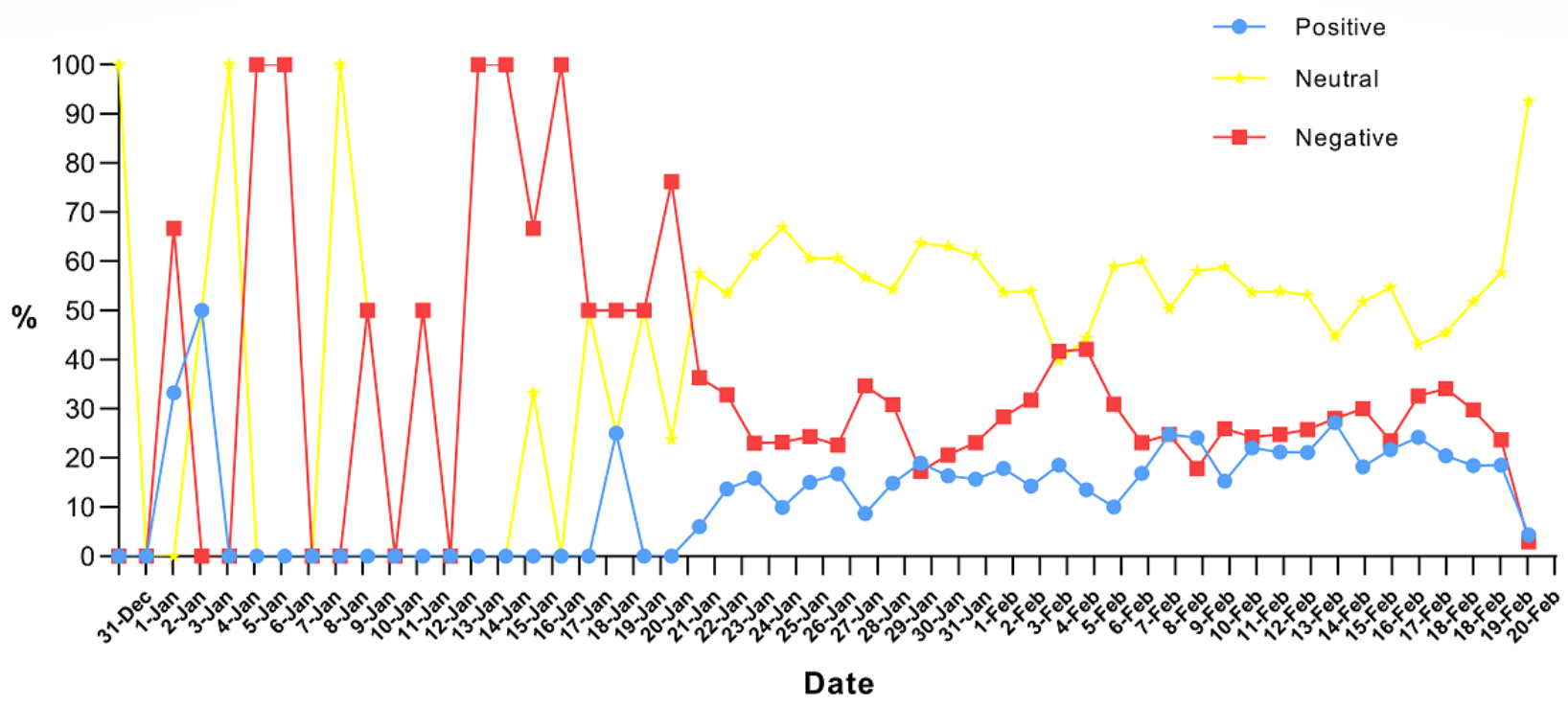

\section{Social Semantic Network Analysis of Hot Search Topics Related to the COVID-19 Epidemic on Sina Microblog}

To explore the themes reflected by the related topics of the COVID-19 epidemic on the Sina Microblog hot search list, this study used VOSviewer to generate clusters and co-occurrence networks of topic keywords. The results are shown in Figure 4. In the figure, the larger the size of the nodes and the font, the greater the weight of the keyword is, and it is closer to the core position. The connection between the nodes indicates that the keywords on the two nodes have appeared together. The thicker the connection is, the higher the frequency of co-occurrence and the closer the connection is between the nodes. Nodes with the same color belong to the same cluster.
According to the network visualization graph constructed in Figure 4, we can see that the keyword "COVID-19" is at the core node position, and the two nodes "Wuhan" and "add" are next. The core topic of public concern about the COVID-19 epidemic was COVID-19 itself, and the public was extremely concerned about the status of the epidemic in Wuhan and the new cases. We can divide the high-frequency keywords of topics into five clusters.

Cluster 1 (red cluster) involved discussion related to new cases, the outbreak of COVID-19 across the country, and the impact of the epidemic on the resumption of school and work. Examples of keywords included "case," "newly increased," "appear," "Hubei Province," and "Beijing” (Figure 5). 
Figure 4. Social network of high-frequency keywords in the Sina Microblog hot search topics related to the COVID-19 epidemic.

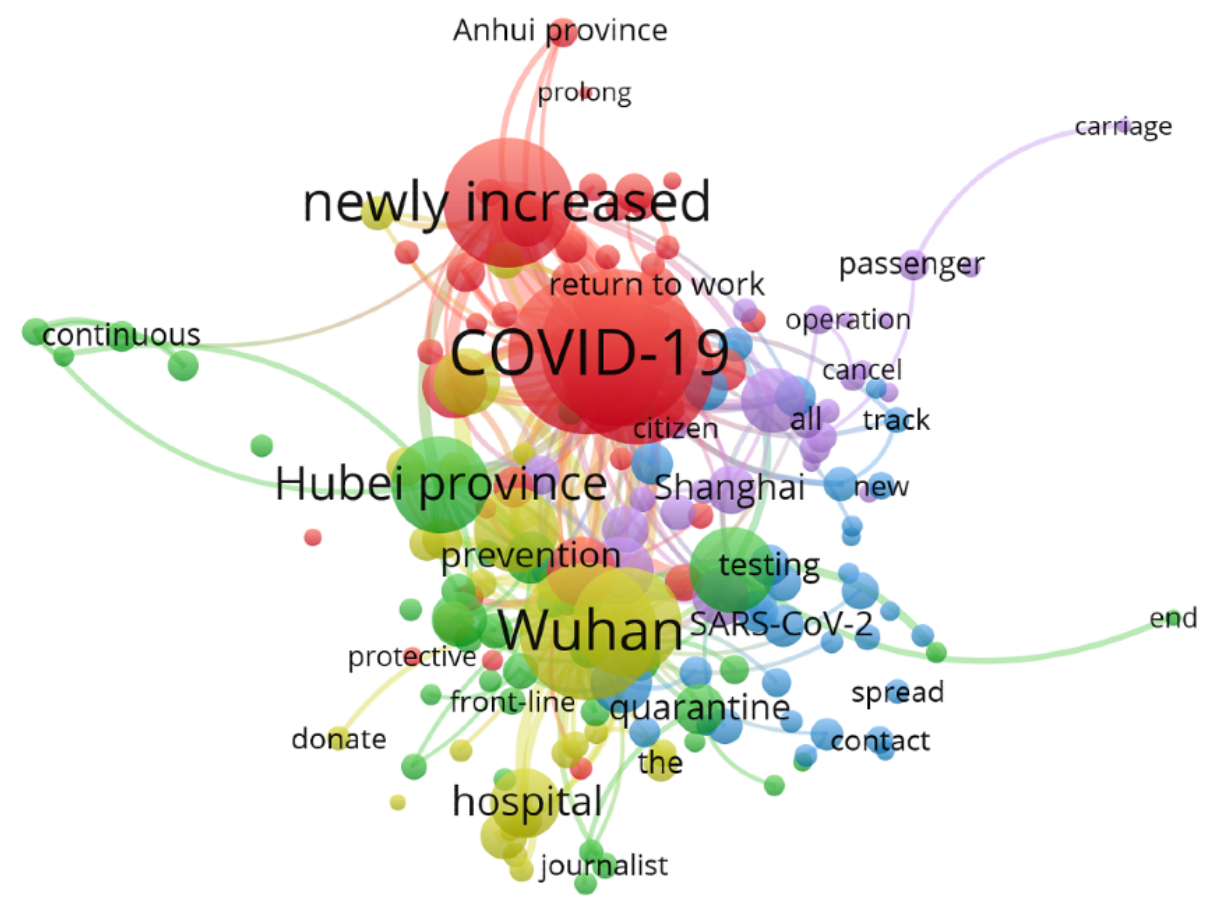

Figure 5. Cluster 1.

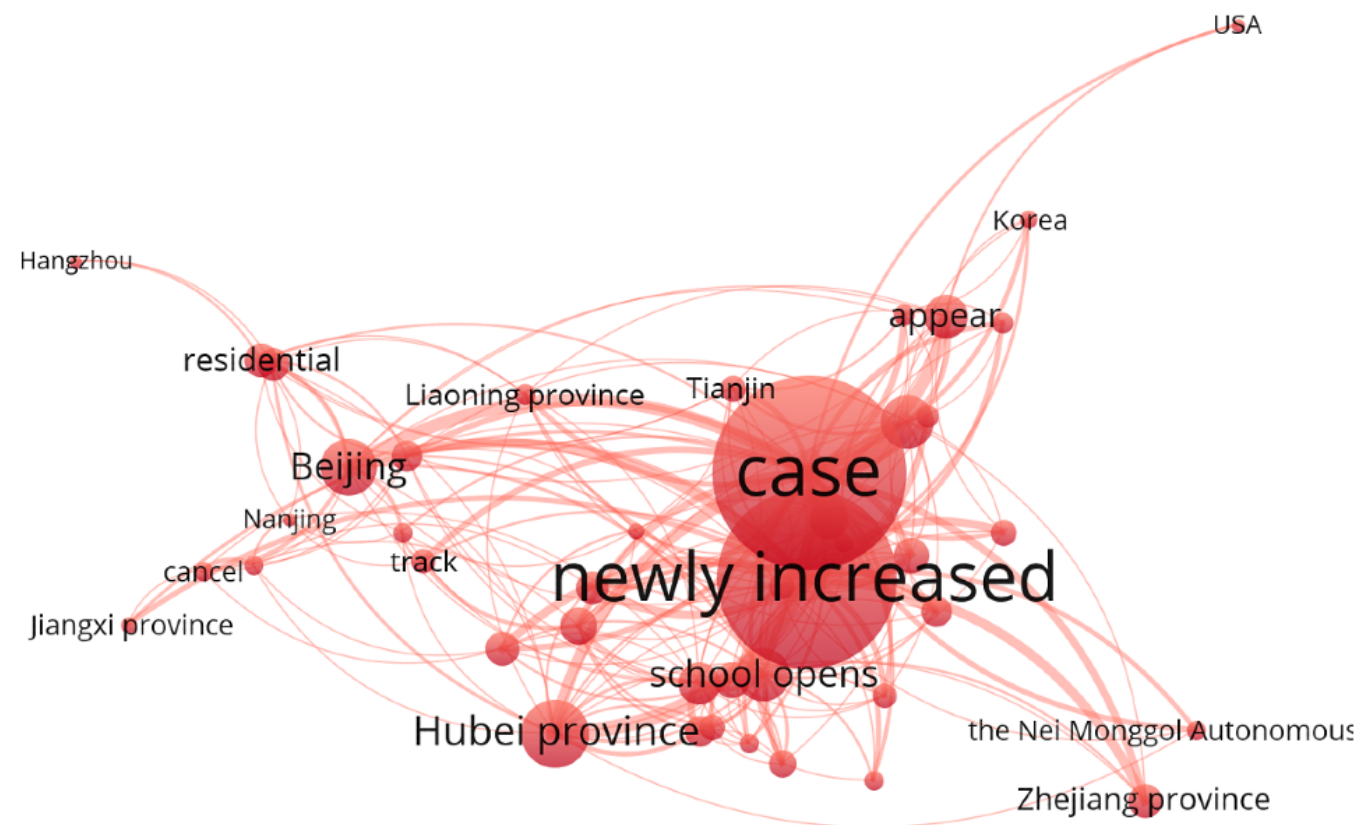

Cluster 2 (green cluster) involved searches for news reports on the frontline of the epidemic and related measures for prevention and control. Examples of keywords included "Wuhan," "front-line," "inpatient," "quarantine," and "living at home" (Figure 6).

Cluster 3 (blue cluster) involved searches for interpretations of the epidemic situation and prevention and control, and the knowledge of experts and relevant health departments, as well as the discussion on the source of the infection. The keywords in this cluster included "academician," "WHO," "face mask," "epidemic prevention," "symptom," "virus," and "SARS-CoV-2" (Figure 7).
Cluster 4 (yellow cluster) included searches for frontline medical services such as frontline hospital construction and medical team support. Examples of keywords in this cluster included "patient," "hospital," "Leishenshan," "Huoshenshan," and "first batch" (Figure 8).

Cluster 5 (purple cluster) included searches for the worldwide spread of the disease and searching online for fellow passengers with confirmed cases. Examples of keywords in this cluster included "passenger," "carriage," "cruise," "suspend," "infection," and "Japan" (Figure 9). 
Figure 6. Cluster 2.

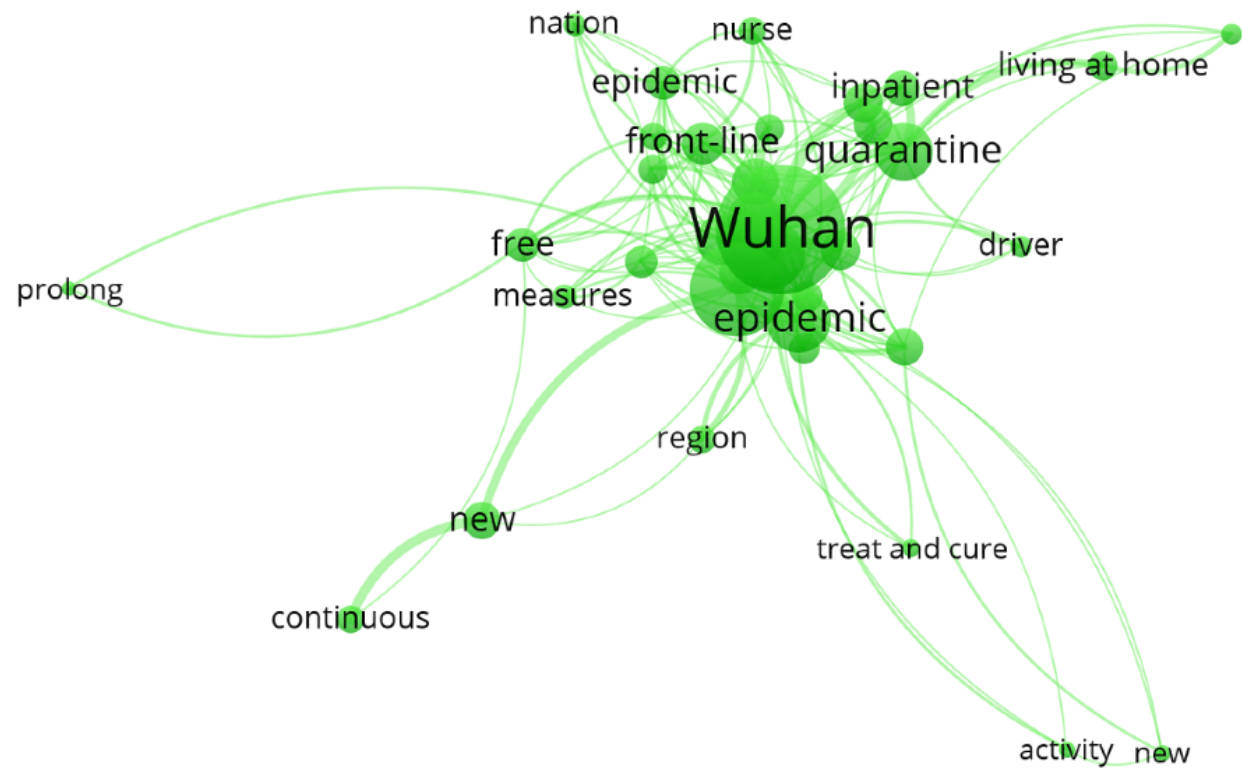

Figure 7. Cluster 3.

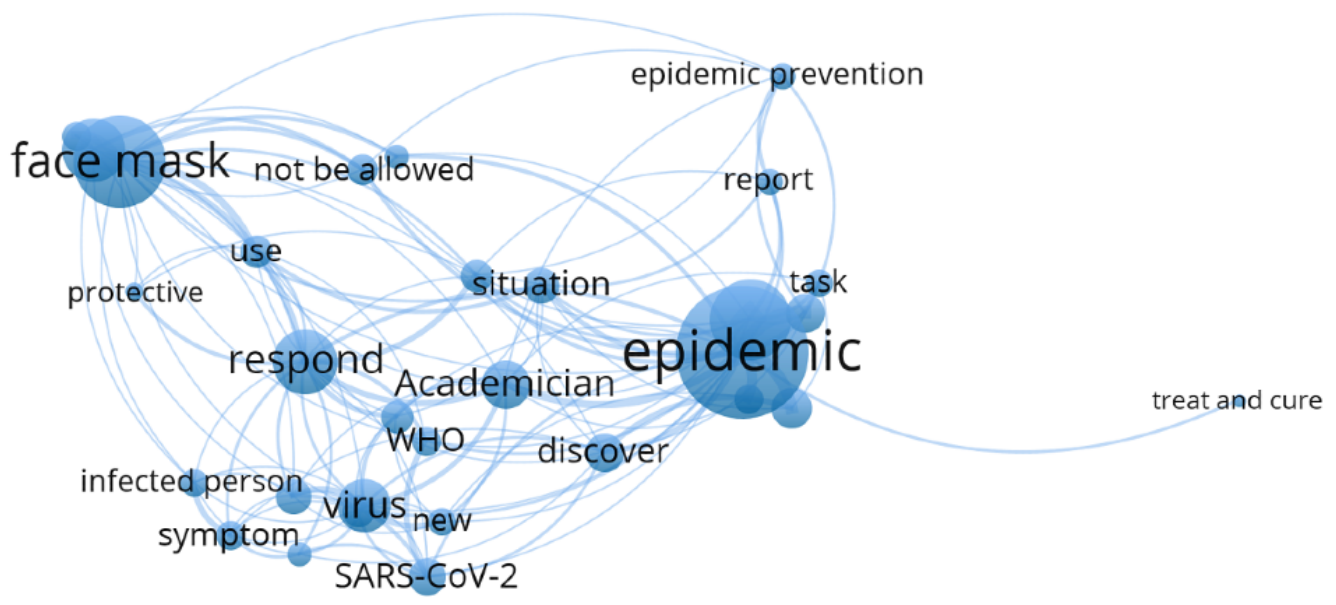


Figure 8. Cluster 4.

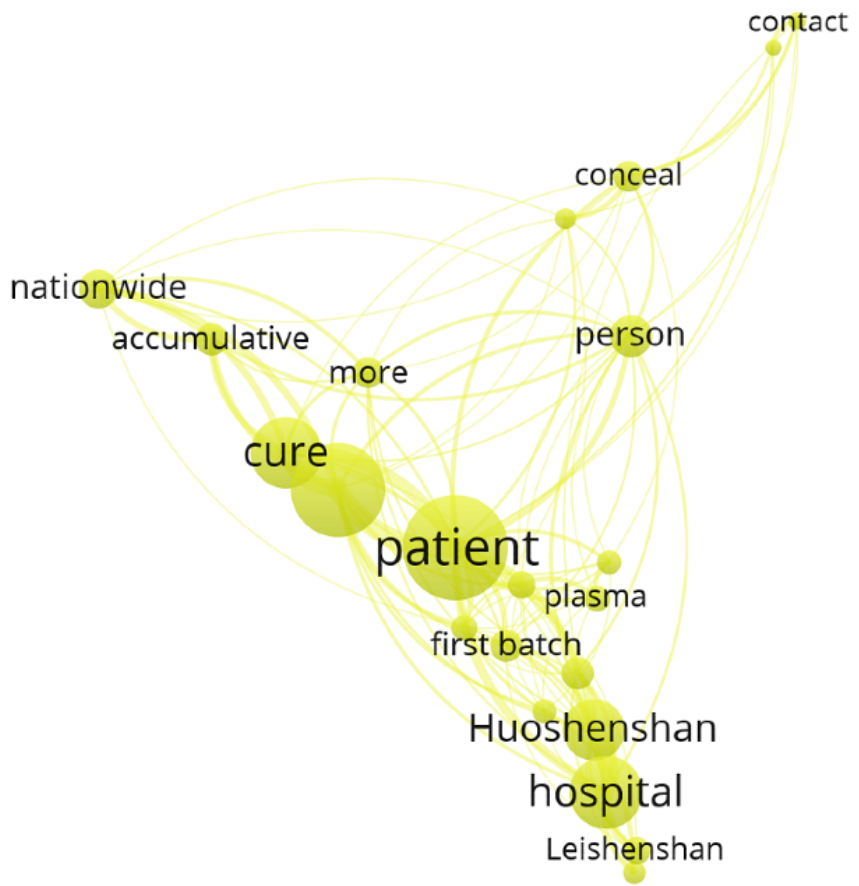

Figure 9. Cluster 5.

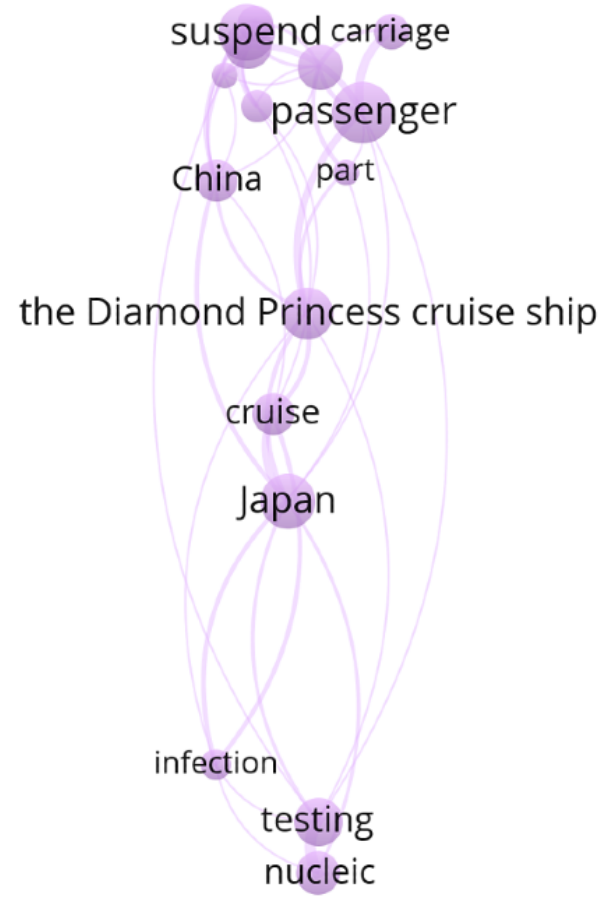

\section{Discussion}

\section{Principal Results}

In recent years, as people increasingly seek health information online, social media has played an increasingly important role in public health emergencies $[29,35]$. However, there have been no relevant studies that have incorporated social media analysis into the public response to the COVID-19 epidemic. We used the Sina Microblog hot search list to analyze the public's attention toward the COVID-19 epidemic from December 31, 2019, to February 20, 2020, which was 52 days after the first disclosure of COVID-19 by the Chinese health department. There were four main findings from this study. First, we analyzed the changing trend of public attention given to the COVID-19 epidemic, which can be divided into three stages. Second, the hot topic keywords of the public's attention at each stage were slightly different. Third, the public's emotional tendency toward the hot search topics related to the COVID-19 epidemic changed from negative to neutral across the study period. As a whole, negative emotions weakened, and positive emotions increased. Fourth, we divided the topics of public concern about the COVID-19 epidemic into five categories through social semantic network analysis. This study analyzes 
the public's response and attention given to the COVID-19 epidemic, which will help public health professionals monitor public response, identify public needs as early as possible, make timely public health prevention and control measures, and disseminate knowledge to citizens in a targeted manner to better respond to the current COVID-19 epidemic.

From December 31, 2019, to February 20, 2020, the public attention given to the COVID-19 epidemic on Sina Microblog can be divided into three stages. In the beginning, there was little public attention paid to the epidemic, and then the concentration of attention increased. Next, the public attention given to the epidemic generally declined, but people continued to pay attention. In the first stage (December 31, 2019, to January 18, 2020), the Chinese public paid less attention, as COVID-19 was only reported in Wuhan, China. On January 19, 2020, suspected cases appeared in Shanghai and Shenzhen, and body temperatures began to be measured at the Wuhan Airport and Railway Station. People began to notice the severity of the epidemic, and the level of attention paid to the COVID-19 epidemic began to increase until January 26, 2020. We can see that when the epidemic began to spread across the country, the public responded quickly to news about the COVID-19 outbreak on Sina Microblog [39]. This is because COVID-19 is a new infectious disease, which means that no effective treatment has been found and no corresponding vaccine has been developed. When the outbreak began, the public was eager to search for relevant knowledge and information online to meet their own protection needs [27,30]. In the third stage (January 27 to February 20,2020), although the number of cases of COVID-19 were still increasing, the number of Sina Microblog topics and their search volume were decreasing. The reason for this may be because the epidemic information was relatively saturated, and it was difficult for people to acquire more new knowledge through a Sina Microblog search [27]. It may also be that people were no longer paying close attention to the epidemic dynamic to gain a sense of security as time went on, and the public's consciousness tends to be rational [52].

The keywords for the three different stages of the public's attention to the COVID-19 epidemic were slightly different. From the hot search keywords of each stage, we found that the public did not know much about the virus and its causes in the first stage. The main keywords of the search to seek relevant knowledge were "unknown cause" and "novel coronavirus." During the second stage, the epidemic began to spread throughout the country, the first cases were reported in different areas successively, and the number of confirmed cases continued to increase, thereby making the public and government aware of the importance of prevention. During the third stage, the epidemic spread widely throughout the country; Wuhan was the most seriously affected area, and the city was locked down. The public's attention was mainly shifted to material donation and medical assistance in Wuhan. Compared with qualitative research, it is more accurate to obtain the hot spots of public attention through keyword frequency analysis, as this process has a higher accuracy and more credibility in the research of hot spots and their development trends [40]. Based on our high-frequency keyword analysis of the Sina Microblog topics related to the COVID-19 epidemic, we can obtain information about the concerns and opinions of Sina Microblog users at different stages [53]. Studies have found that people's interest in infectious diseases on social media was linked to the latest news and major events. Studies have also shown that people will pay attention to and search for disease-related words as the spread of infectious diseases change [30].

According to the sentiment tendencies of the hot search topics related to the COVID-19 epidemic on Sina Microblog, the first stage of emotion was negative, and the second and third stages were neutral. On the whole, negative emotions weakened, and positive emotions increased. Previous studies have pointed out that there is also an important relationship between emotions and content on social media [54]. The content analysis of social networks has identified people's attitudes or reactions to specific health hazard events [30,39]. In the first stage, there was less public attention given to the Sina Microblog hot search list. Most of the topics related to the COVID-19 epidemic were about the notification of pneumonia and the virus, and the emotions tended to be negative. At that time, the public had a strong demand for information on public health emergencies such as infectious diseases. When the information demand could not be fully satisfied, the users' emotions were negative [40]. As the epidemic progressed to the second and third stages, the public sentiment tended to be neutral because increasingly more news was being reported at this stage, and objective events became the mainstream information on the Sina Microblog hot search list. The public reduced their previous levels of worries and fears about the epidemic; their negative feelings weakened, and their positive emotions increased. More hot search topics mentioned information about prevention or protection, which is conducive to public health communication and promotion.

We divided the COVID-19 topics with the highest levels of public concern into five categories: the situation of new cases of COVID-19 and its impact, frontline reporting of the epidemic and the measures of prevention and control, expert interpretation and discussion on the source of infection, medical services on the frontline of the epidemic, and focus on the worldwide epidemic and looking for suspected cases. From the search of the subject content, we can see that during the outbreak of the novel coronavirus, the public, the news media, and the health department all actively used Sina Microblog as a platform for disseminating information related to COVID-19 [29], indicating that Sina Microblog is a communication channel for both individuals and organizations to publicize COVID-19 symptoms, preventive measures, and related policies [37]. In addition, as a real time and extensive online platform, Sina Microblog provides a channel for information dissemination. For example, in this emergency outbreak, the public has made good use of the platform to find fellow passengers with confirmed cases, thereby playing an important role in preventing and controlling the disease transmission.

\section{Limitations}

There are some limitations to this study. First, our study was limited to the period 52 days after COVID-19 was first disclosed by the Chinese health department. Thus, the situation after February 20, 2020, was not included in this study. Second, we only used Sina Microblog as the social media platform in this 
study, the data source for this study is relatively narrow. Considering that China is seriously aging and that the majority of internet users are young people, the age of Sina Microblog users is mainly concentrated in those 18-41 years [42], which cannot represent the population of all ages in China. Therefore, selection bias is inevitable in this study. On the other hand, the study excludes other popular social media data sources such as WeChat and ByteDance and is limited to the publicly available data on the Sina Microblog hot search list. Moreover, due to the lack of detailed information about the users who contributed to the search volume of the Sina Microblog hot search list, we could not describe the social demographic information of the Sina Microblog users, and we failed to obtain the geospatial distribution of Sina Microblog active users. Thus, we could not calculate the average attention of the public in different regions of China.

\section{Future Work}

Social media has played a vital role during the spread of the COVID-19 epidemic and has become the main way for the public to obtain epidemic information. However, the excessive amount of information about the novel coronavirus (some right, some wrong) on social media may make it difficult for people to find reliable sources and guidance when needed, and may even be harmful to people's health, leading to the outbreak of an infodemic [55]. Therefore, misinformation can be easily propagated and spread on social media. Apart from traditional "top-down" public health communication, provider-managed communication platforms such as WebMD (America), AskDr (Singapore), and HaoDF (China) can be used as an additional countermeasure available to develop a ground-up response to this issue. HaoDF [56], one of the largest doctor-patient communication platforms in China, launched an online free consultation service for COVID-19 during this epidemic. Doctors answered questions online for free 24 hours a day to help the public make a preliminary judgment about the disease and avoid blind medical treatment caused by panic. In addition, HaoDF summarized the common questions and answers of COVID-19 to let the public know more about the epidemic. These are the forms of responses, as potential solutions to avoid an infodemic, that governments can engage with, researchers can study, and innovators can develop in the future.

\section{Conclusions}

Our study found that social media platforms such as Sina Microblog can be used to measure public attention given to public health emergencies. Our study shows that a large amount of information about the COVID-19 epidemic was disseminated and received widespread public attention on Sina Microblog during the novel coronavirus epidemic. We have learned about the hotspots of public concern regarding the COVID-19 epidemic on Sina Microblog. These findings can help the government and health departments better communicate with the public about public health and then translate public health needs into practice to create targeted measures to prevent and control the spread of COVID-19.

\section{Conflicts of Interest}

None declared.

\section{References}

1. Special Expert Group for Control of the Epidemic of Novel Coronavirus Pneumonia of the Chinese Preventive Medicine Association. [An update on the epidemiological characteristics of novel coronavirus pneumonia (COVID-19)]. Zhonghua Liu Xing Bing Xue Za Zhi 2020 Feb 14;41(2):139-144. [doi: 10.3760/cma.j.issn.0254-6450.2020.02.002] [Medline: 32057211]

2. Wuhan Municipal Health Committee. Report of Wuhan Municipal Health Committee on viral pneumonia of unknown cause [in Chinese] URL: http://wjw.wuhan.gov.cn/front/web/showDetail/2020011109035 [accessed 2020-02-21]

3. World Health Organization. 2020 Jan 31. Novel Coronavirus (2019-nCoV) Situation Report - 11 URL: https://www.who.int/ docs/default-source/coronaviruse/situation-reports/20200131-sitrep-11-ncov.pdf?sfvrsn=de7c0f7 4 [accessed 2020-02-21]

4. National Health Commission of the people's Republic of China. Pneumonia situation in novel coronavirus infection on January 21st [in Chinese] URL: http://www.nhc.gov.cn/xcs/yqtb/202001/930c021cdd1f46dc832fc27e0cc465c8.shtml [accessed 2020-02-21]

5. Sun K, Chen J, Viboud C. Early epidemiological analysis of the coronavirus disease 2019 outbreak based on crowdsourced data: a population-level observational study. The Lancet Digital Health 2020 Apr;2(4):e201-e208. [doi: $10.1016 / \mathrm{s} 2589-7500(20) 30026-1]$

6. Xu B, Kraemer MUG, Xu B, Gutierrez B, Mekaru S, Sewalk K, et al. Open access epidemiological data from the COVID-19 outbreak. The Lancet Infectious Diseases 2020 Feb:e. [doi: 10.1016/s1473-3099(20)30119-5]

7. Lipsitch M, Swerdlow DL, Finelli L. Defining the epidemiology of Covid-19 — studies needed. N Engl J Med 2020 Mar 26;382(13):1194-1196. [doi: 10.1056/nejmp2002125]

8. El-Tholoth M, Bau HH, Song J. A single and two-stage, closed-tube, molecular test for the 2019 Novel Coronavirus (COVID-19) at home, clinic, and points of entry. ChemRxiv 2020:e. [doi: 10.26434/chemrxiv.11860137]

9. Li Q, Ding X, Xia G, Geng Z, Chen F, Wang L, et al. A simple laboratory parameter facilitates early identification of COVID-19 patients. medRxiv 2020:e. [doi: 10.1101/2020.02.13.20022830]

10. To K, Tsang O, Chik-Yan Yip C, Chan KH, Wu TC, Chan JMC, et al. Consistent detection of 2019 novel coronavirus in saliva. Clin Infect Dis 2020 Feb 12:e [FREE Full text] [doi: 10.1093/cid/ciaa149] [Medline: $\underline{\text { 32047895] }}$ 
11. Yang Y, Yang M, Shen C, Wang F, Yuan J, Li J, et al. Evaluating the accuracy of different respiratory specimens in the laboratory diagnosis and monitoring the viral shedding of 2019-nCoV infections. medRxiv 2020:e. [doi: $10.1101 / 2020.02 .11 .20021493$

12. Pan X, Chen D, Xia Y, Wu X, Li T, Ou X, et al. Asymptomatic cases in a family cluster with SARS-CoV-2 infection. The Lancet Infectious Diseases 2020 Apr;20(4):410-411. [doi: 10.1016/s1473-3099(20)30114-6]

13. Xu X, Wu X, Jiang X, Xu K, Ying L, Ma C, et al. Clinical findings in a group of patients infected with the 2019 novel coronavirus (SARS-Cov-2) outside of Wuhan, China: retrospective case series. BMJ 2020 Feb 19;368:m606. [doi: 10.1136/bmj.m606] [Medline: $\underline{32075786]}$

14. Silverstein WK, Stroud L, Cleghorn GE, Leis JA. First imported case of 2019 novel coronavirus in Canada, presenting as mild pneumonia. The Lancet 2020 Feb;395(10225):734. [doi: 10.1016/s0140-6736(20)30370-6]

15. Pan F, Ye T, Sun P, Gui S, Liang B, Li L, et al. Time course of lung changes on chest CT during recovery from 2019 novel coronavirus (COVID-19) pneumonia. Radiology 2020 Feb 13:e. [doi: 10.1148/radiol.2020200370]

16. Fang Y, Zhang H, Xu Y, Xie J, Pang P, Ji W. CT manifestations of two cases of 2019 novel coronavirus (2019-nCoV) pneumonia. Radiology 2020 Apr;295(1):208-209. [doi: 10.1148/radiol.2020200280] [Medline: 32031481]

17. Liang W, Guan W, Chen R, Wang W, Li J, Xu K, et al. Cancer patients in SARS-CoV-2 infection: a nationwide analysis in China. The Lancet Oncology 2020 Mar;21(3):335-337. [doi: 10.1016/s1470-2045(20)30096-6]

18. Chen J. Pathogenicity and transmissibility of 2019-nCoV-a quick overview and comparison with other emerging viruses. Microbes Infect 2020 Mar;22(2):69-71. [doi: 10.1016/j.micinf.2020.01.004] [Medline: $\underline{32032682]}$

19. Mizumoto K, Kagaya K, Chowell G. Early epidemiological assessment of the transmission potential and virulence of 2019 Novel Coronavirus in Wuhan City: China, 2019-2020. medRxiv 2020:e. [doi: 10.1101/2020.02.12.20022434]

20. Micholas S, Jeremy C. Repurposing therapeutics for COVID-19: supercomputer-based docking to the SARS-CoV-2 viral spike protein and viral spike protein-human ACE2 interface. ChemRxiv 2020:e. [doi: 10.26434/chemrxiv.11871402.v3]

21. Anh-Tien T, Francesco G, Michael H, Fuqiang B, Artem C. Rapid identification of potential inhibitors of SARS-CoV-2 main protease by deep docking of 1.3 billion compounds. ChemRxiv 2020:e. [doi: 10.26434/chemrxiv.11860077]

22. Rimanshee A, Amit D, Vishal P, Mukesh K. Potential inhibitors against papain-like protease of novel coronavirus (SARS-CoV-2) from FDA approved drugs. ChemRxiv 2020:e. [doi: 10.26434/chemrxiv.11860011]

23. Liu P, Jiang JZ, Wan XF, Hua Y, Wang X, Hou F, et al. Are pangolins the intermediate host of the 2019 novel coronavirus (2019-nCoV)? bioRxiv 2020:e. [doi: 10.1101/2020.02.18.954628]

24. Xiao K, Zhai J, Feng Y, Zhou N, Zhang X, Zou JJ, et al. Isolation and characterization of 2019-nCoV-like coronavirus from Malayan pangolins. bioRxiv 2020:e. [doi: 10.1101/2020.02.17.951335]

25. Lam T, Shum M, Zhu H, Tong YG, Ni XB, Liao YS, et al. Identification of 2019-nCoV related coronaviruses in Malayan pangolins in southern China. bioRxiv 2020:e. [doi: 10.1101/2020.02.13.945485]

26. Wong M, Javornik CS, Ajami N, Petrosino J. Evidence of recombination in coronaviruses implicating pangolin origins of nCoV-2019. bioRxiv 2020:e. [doi: 10.1101/2020.02.07.939207]

27. Gu H, Chen B, Zhu H, Jiang T, Wang X, Chen L, et al. Importance of Internet surveillance in public health emergency control and prevention: evidence from a digital epidemiologic study during avian influenza A H7N9 outbreaks. J Med Internet Res 2014 Jan 17;16(1):e20 [FREE Full text] [doi: 10.2196/jmir.2911] [Medline: 24440770]

28. Househ M. Communicating Ebola through social media and electronic news media outlets: a cross-sectional study. Health Informatics J 2016 Sep;22(3):470-478. [doi: 10.1177/1460458214568037] [Medline: 25656678]

29. Gui X, Wang Y, Kou Y, Reynolds TL, Chen Y, Mei Q, et al. Understanding the patterns of health information dissemination on social media during the Zika outbreak. AMIA Annu Symp Proc 2017;2017:820-829 [FREE Full text] [Medline: 29854148]

30. Chen Y, Zhang Y, Xu Z, Wang X, Lu J, Hu W. Avian Influenza A (H7N9) and related Internet search query data in China. Sci Rep 2019 Jul 18;9(1):10434. [doi: 10.1038/s41598-019-46898-y] [Medline: 31320681]

31. Xie T, Yang Z, Yang S, Wu N, Li L. Correlation between reported human infection with avian influenza A H7N9 virus and cyber user awareness: what can we learn from digital epidemiology? Int J Infect Dis 2014 May;22:1-3. [doi: 10.1016/j.ijid.2013.11.013] [Medline: 24576842]

32. Fung IC, Fu K, Chan C, Chan BSB, Cheung C, Abraham T, et al. Social media's initial reaction to information and misinformation on Ebola, August 2014: facts and rumors. Public Health Rep 2016;131(3):461-473 [FREE Full text] [doi: 10.1177/003335491613100312] [Medline: 27252566]

33. Fung IC, Duke CH, Finch KC, Snook KR, Tseng P, Hernandez AC, et al. Ebola virus disease and social media: a systematic review. Am J Infect Control 2016 Dec 01;44(12):1660-1671. [doi: 10.1016/j.ajic.2016.05.011] [Medline: 27425009]

34. Wong R, Harris JK. Geospatial distribution of local health department tweets and online searches about Ebola during the 2014 Ebola outbreak. Disaster Med Public Health Prep 2018 Jun;12(3):287-290. [doi: 10.1017/dmp.2017.69] [Medline: 28835312]

35. Feng S, Hossain L, Crawford JW, Bossomaier T. Quantifying Network Dynamics and Information Flow Across Chinese Social Media During the African Ebola Outbreak. Disaster med. public health prep 2017 Aug 01;12(1):26-37. [doi: 10.1017/dmp.2017.29]

36. Seltzer E, Jean N, Kramer-Golinkoff E, Asch D, Merchant R. The content of social media's shared images about Ebola: a retrospective study. Public Health 2015 Sep;129(9):1273-1277. [doi: 10.1016/j.puhe.2015.07.025] [Medline: 26285825] 
37. Seltzer E, Horst-Martz E, Lu M, Merchant R. Public sentiment and discourse about Zika virus on Instagram. Public Health 2017 Sep;150:170-175. [doi: 10.1016/j.puhe.2017.07.015] [Medline: 28806618]

38. Fu K, Liang H, Saroha N, Tse ZTH, Ip P, Fung IC. How people react to Zika virus outbreaks on Twitter? A computational content analysis. Am J Infect Control 2016 Dec 01;44(12):1700-1702. [doi: 10.1016/j.ajic.2016.04.253] [Medline: 27566874]

39. Fung IC, Fu K, Ying Y, Schaible B, Hao Y, Chan C, et al. Chinese social media reaction to the MERS-CoV and avian influenza A(H7N9) outbreaks. Infect Dis Poverty 2013 Dec 20;2(1):31. [doi: 10.1186/2049-9957-2-31] [Medline: 24359669]

40. Wang XY, Hao YH, Wu QH, Xu W, Wang XF, Dai YJ, et al. Visual analysis of official microblogging network public opinion on Dengue events [in Chinese]. Chinese Preventive Medicine 2018;19(06):401-406. [doi: 10.16506/j.1009-6639.2018.06.001]

41. World Health Organization. Coronavirus disease (COVID-19) technical guidance: risk communication and community engagement URL: https://www.who.int/emergencies/diseases/novel-coronavirus-2019/technical-guidance/ risk-communication-and-community-engagement [accessed 2020-04-13]

42. Sina microblog data center. 2018 Sina microblog user development report [in Chinese] URL: https://data.weibo.com/report/ reportDetail?id=433 [accessed 2020-02-21]

43. Chen Y. Analysis of the social functions of microblog hot search in the perspective of development communication [in Chinese]. Research on Transmission Competence 2019;3(04):76.

44. Zhang Y. Analysis of the reasonability of microblog hot search list in the perspective of communication [in Chinese]. Journal of News Research 2018;9(16):29-31.

45. Hu G, Han X, Zhou H, Liu Y. Public perception on healthcare services: evidence from social media platforms in China. Int J Environ Res Public Health 2019 Apr 10;16(7):e. [doi: 10.3390/ijerph16071273] [Medline: $\underline{30974729]}$

46. National Health Commission of the People's Republic of China. Efforts to prevent and control epidemic situation of COVID-19 [in Chinese] URL: http://www.nhc.gov.cn/xcs/yqtb/list_gzbd.shtml [accessed 2020-02-21]

47. Wuhan Municipal Health Committee. Report of Wuhan Municipal Health Committee on the current situation of pneumonia in our city [in Chinese] URL: http://wjw.wuhan.gov.cn/front/web/showDetail/2019123108989 [accessed 2020-02-21]

48. Weibo Search Rank [in Chinese]. URL: https://www.enlightent.cn/research/rank/weiboSearchRank [accessed 2020-02-21]

49. ENLIGHTENT [in Chinese]. URL: https://www.enlightent.cn/ [accessed 2020-02-21]

50. Fang Q. Research on the impact of ROST Content Mining System on content analysis [in Chinese]. Course Education Research 2014(01):234-235. [doi: 10.1093/oxfordhb/9780199811755.013.008]

51. VOSviewer - Visualizing scientific landscapes. URL: https://www.vosviewer.com/ [accessed 2020-02-21]

52. Liu B, Wang Z, Qi X, Zhang X, Chen H. Assessing cyber-user awareness of an emerging infectious disease: evidence from human infections with avian influenza A H7N9 in Zhejiang, China. Int J Infect Dis 2015 Nov;40:34-36. [doi: 10.1016/j.ijid.2015.09.017] [Medline: 26432409]

53. Lazard AJ, Wilcox GB, Tuttle HM, Glowacki EM, Pikowski J. Public reactions to e-cigarette regulations on Twitter: a text mining analysis. Tob Control 2017 Dec;26(e2):e112-e116. [doi: 10.1136/tobaccocontrol-2016-053295] [Medline: 28341768]

54. Massey PM, Leader A, Yom-Tov E, Budenz A, Fisher K, Klassen AC. Applying multiple data collection tools to quantify human papillomavirus vaccine communication on Twitter. J Med Internet Res 2016 Dec 05;18(12):e318 [FREE Full text] [doi: 10.2196/jmir.6670] [Medline: 27919863]

55. Zarocostas J. How to fight an infodemic. The Lancet 2020 Feb;395(10225):676. [doi: 10.1016/s0140-6736(20)30461-x]

56. HaoDF [in Chinese]. URL: https://www.haodf.com/ [accessed 2020-04-13]

\section{Abbreviations}

COVID-19: coronavirus disease

ROST CM6.0: ROST Content Mining System version 6.0

SARS-CoV-2: severe acute respiratory syndrome coronavirus 2

WHO: World Health Organization

Edited by G Eysenbach; submitted 23.03.20; peer-reviewed by D Gunasekeran, Y Liu; comments to author 09.04.20; revised version
received 13.04.20; accepted 20.04.20; published 04.05.20
Please cite as:
Zhao Y, Cheng S, Yu X, Xu H
Chinese Public's Attention to the COVID-19 Epidemic on Social Media: Observational Descriptive Study
J Med Internet Res 2020;22(5):e18825
URL: $\underline{\text { https://www.jmir.org/2020/5/e18825 }}$
doi: $10.2196 / 18825$
PMID: $\underline{32314976}$


(C) Yuxin Zhao, Sixiang Cheng, Xiaoyan Yu, Huilan Xu. Originally published in the Journal of Medical Internet Research (http://www.jmir.org), 04.05.2020. This is an open-access article distributed under the terms of the Creative Commons Attribution License (https://creativecommons.org/licenses/by/4.0/), which permits unrestricted use, distribution, and reproduction in any medium, provided the original work, first published in the Journal of Medical Internet Research, is properly cited. The complete bibliographic information, a link to the original publication on http://www.jmir.org/, as well as this copyright and license information must be included. 